\title{
Fatigue Behavior and Fracture Mechanism of a Hot Rolled AA7020 Aluminum Alloy
}

\author{
Ashish Thakur* \\ Department of Mechanical Engineering, Solid Mechanics and Design Chair, Ethiopian Institute of Technology, Mekelle University, Mekelle, \\ Ethiopia
}

Received 08 March 2019, Accepted 11 May 2019, Available online 13 May 2019, Vol.9, No.3 (May/June 2019)

\begin{abstract}
Fatigue tests of smooth specimens and CT specimens of a hot rolled AA7020 Aluminum alloy have been performed in laboratory at ambient temperature. Fatigue strength and fatigue crack propagation (FCP) characteristic were evaluated and fracture mechanism was discussed on the basis of crack initiation, small crack growth, and fracture surface analysis. The growth behavior of small and large cracks has been investigated on 7020 alloy.The FCP resistance was found significantly lower than that of other aluminum alloys. The crack growth measurements were performed in CT specimens at constant load ratios ranging from $R=0.1-0.5$. The fatigue strength at $10^{4}$ cycles was $110 \mathrm{MPa}$ that led to a considerably fatigue ratio of 0.1, fatigue failure did not occur. There existed two different modes of crack initiation depending on applied stress level. Above $200 \mathrm{MPa}$, cracks initiated at the specimen surface in transgranular or intergranular manner due to cyclic slip deformation, while below that stress subsurface crack initiation took place. The growth of small cracks initiated at the surface coincided with the FCP characteristic after allowing for crack closure for large cracks, but the operative fracture mechanisms were different between small and large cracks.
\end{abstract}

Keywords: Fatigue strength, Aluminum alloy, Crack initiation, Crack growth, Subsurfacefracture

\section{Introduction}

Al-alloys, such as 2024 (T3), 7075 (T6), and 6061 (T6) contain numerous constituent particles of brittle phases dispersed in the ductile matrix, which play an important role in void formation (Wang QY et al, 2003). When ductile materials are subjected to static or cyclic loads, the fatigue (ductile) fracture may result from the nucleation, growth and coalescence of microvoids. Structural Al-alloys are used extensively in automotive and aircraft industries. The required design lifetime of many engines, wheels, chassis, and body components often exceeds $10^{9}$ cycles (giga cycle range) (Heuler P. et al, 2002). Therefore, they have recently been increasing interest as structural materials in many applications, in particular, they are considered to be replacing aluminium alloys with a concomitant saving in weight in automotive industries. For applications to load-bearing components, it is necessary to evaluate various fatigue properties. When considered such situation of fatigue research and the recent development of $\mathrm{Al}$ alloys, the accumulation of various fatigue data is now of particular importance. Al alloys can be classified into two categories, casting and

*Corresponding author's ORCID ID: 0000-0001-9287-700X DOI: https://doi.org/10.14741/ijcet/v.9.3.8 wrought alloys. In casting alloys, defects such as casting porosity and cavity are usually present and the fatigue properties are affected significantly by their shape and dimension (Mayer H. et al, 2003). On the contrary, wrought alloys are defect-free and thus the evaluation of their fatigue properties is of great interest to understand the intrinsic fatigue mechanism of $\mathrm{Al}$ alloys. During the past two decades, numerous studies of the growth behavior of small cracks ( typically $0.01-1 \mathrm{~mm}$ ) size have revealed that the small crack propagation rates are often greater than those of large cracks at the at the same applied stress intensity factor range $\Delta \mathrm{K}$ and the small crack grow at $\Delta \mathrm{K}$ values below the large crack threshold.

The materials used for automotive or aerospace applications are mostly subject to cyclic loading, sometimes involving high frequency vibrations. They are also usually required to operate over long periods of life, extending much beyond a million cycles. High strength aluminum alloys are one class of materials that are widely used in the automotive and aerospace industries.

In the present study, axial fatigue tests have been performed using smooth specimens and CT specimens of a hot rolled Al-4.5Zn-1.5Mg alloy in laboratory air at ambient temperature. Fatigue strength and FCP characteristic were evaluated and fracture mechanism 
was discussed on the basis of crack initiation, small crack growth and fracture surface analysis.

\section{Experimental details}

\subsection{Material}

The material for investigation was the Al-Zn-Mg alloy AFNOR 7020(whose composition was as follows: Al4.5\% Zn-1.4\% Mg-0.059\% Zr (wt. \%) supplied from Hindustan Aeronautics Limited and tests were conducted at IIT Bombay, Mechanical Engineering Department, fracture mechanics laboratory. Material, supplied by Hindustan Aeronautics Limited, was received in the form of $5 \mathrm{~mm}$ thick hot rolled plate. A full chemical composition is given in Table 1. Mechanical and physical properties of 7020-T6 at room temperature (fatigue properties for growth perpendicular to rolling direction) are presented (Thakur A. et al, 2007).

Table 1: Chemical composition of the aluminum alloy (masses \%)

\begin{tabular}{|c|c|c|c|c|c|c|c|c|}
\hline $\mathrm{Zn}$ & $\mathrm{Mg}$ & $\mathrm{Si}$ & $\mathrm{Mn}$ & $\mathrm{Zr}$ & $\mathrm{Ti}$ & $\mathrm{Cr}$ & $\mathrm{Cu}$ & Balance \\
\hline 4.35 & 1.4 & 0.012 & 0.22 & 0.059 & 0.012 & 0.032 & 0.06 & 93.885 \\
\hline
\end{tabular}

Figure 1 shows the microstructure of the alloy, which consisted of equiaxed grains and macroscopic anisotropy of the microstructure is not recognized. The average grain size is approximately $40-80 \mu \mathrm{m}$. The mechanical properties in the longitudinal rolling direction are $0.2 \%$ proof stress $\sigma_{0.2}: 280 \mathrm{MPa}$, tensile strength $\sigma_{\mathrm{B}}$ : $383.7 \mathrm{MPa}$, elongation $\varphi: 12-18 \%$.

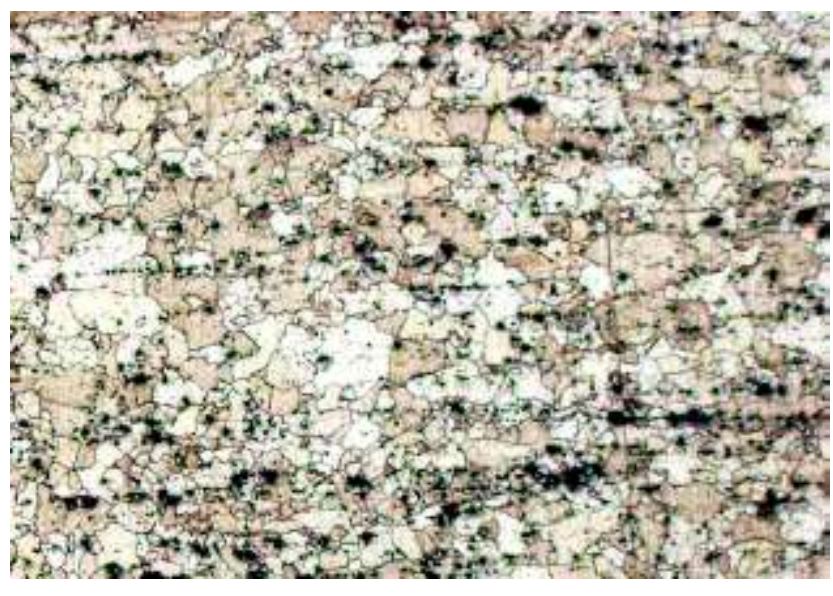

Fig.1.Microstructure of the alloy in rolling direction

\subsection{Specimens}

Fatigue specimens with $8 \pm 0.4 \mathrm{~mm}$ width, $50 \mathrm{~mm}$ gauge length and $5 \mathrm{~mm}$ thickness were machined from asreceived plate so that their axis is parallel to the rolling direction. A blunt notch whose stress concentration factor is 1.15 was introduced on one side of the specimen to facilitate observation of fatigue crack initiation and small crack growth. The surface of the specimens was mechanically polished using a succession of finer grade emery papers $(1 / 0,2 / 0,3 / 0$, $4 / 0$ ) and diamond pastes to a $1 / 4 \mu \mathrm{m}$ finish before fatigue test. The mirror finish was selected in order to minimize secondary crack population. All tests were carried out using specimens oriented with the tension axis parallel to the rolling direction and the fatigue surface perpendicular to the rolling plane. CT specimens with $25.4 \mathrm{~mm}$ width and $5 \mathrm{~mm}$ thickness were also prepared from as-received plate. The FCP direction was perpendicular to the rolling direction, i.e. L-T orientation. After the experiment, fracture surfaces were examined in detail by scanning electron microscope (SEM).

\subsection{Fatigue testing}

Fatigue testing was performed on the $100 \mathrm{KN}$ servohydraulic MTS machine using accelerated fatigue at $20 \mathrm{KHz}$.The specimens were tested in air at room temperature, under zero mean stress. The tests were conducted for different cyclic stresses based on the staircase method. The fatigue stress is actually derived from the displacement amplitude of the vibrating specimen, which is what is measured and monitored through a non-contact fiber optic sensor of $\pm 0.05 \mathrm{Pm}$ resolution. As there was a tendency for the specimen to get heated up during the test, it was subjected to a compressed air blast to maintain its temperature within ambient.

The crack growth measurements were performed in CT specimens at constant load ratios ranging from $R$ $=0.1-0.5$. The test frequency was $12 \mathrm{~Hz}$. Crack growth rates and $K$ were obtained according to the standard test method for measurement of fatigue crack growth rates (ASTM E 647-1999).Crack monitoring was performed using a video camera mounted on an optical microscope and a dedicated image capturing card supported by a computer. Crack measurements were performed using image analysis software Olympus (Sigma Scan by SPSS). The software is based on the tracking of the crack using a mouse. Several crack growth data, $\mathrm{d} a / \mathrm{d} N$, are presented in previous work (Thakur A. et al, 2007).

\section{Results and Discussion}

The growth behaviour of microstructurally small fatigue cracks was investigated with smooth and compact tensile specimens of AA7020.

\subsection{FCP characteristics for large cracks}

The relationships between crack propagation rate, $\mathrm{da} / \mathrm{dN}$, and $\Delta \mathrm{K}$ and effective stress intensity factor range, $\Delta \mathrm{K}_{\mathrm{eff}}$, for large cracks are represented in Figure 2. A great amount of work has been done in determining the fatigue- crack propagation characteristics of aluminum alloy [ASTMSpec. Tech Publ. et al, 1967; Proc. Crack Propagation Symp et al, 
1961]. It is worth noting that the da $/ \mathrm{dN}=\Delta \mathrm{K}$ relationship consists of two sections with different slopes below and above $\Delta \mathrm{K}=5.5-8.5 \mathrm{MPa} \sqrt{\mathrm{m}}$. This tendency becomes much more remarkable when crack closure is taken into account, i.e. FCP rates are characterized in terms of $\Delta \mathrm{K}_{\mathrm{eff}}$, where the slope change occurs at $\Delta \mathrm{K}_{\mathrm{eff}}=3.5-6.0 \mathrm{MPa} \sqrt{\mathrm{m}}$. Similar slope changes in FCP characteristics have also been reported in aluminium alloy (Jono $\mathrm{M}$, et al, 1984) may be related to the transition from structure-sensitive behaviour.

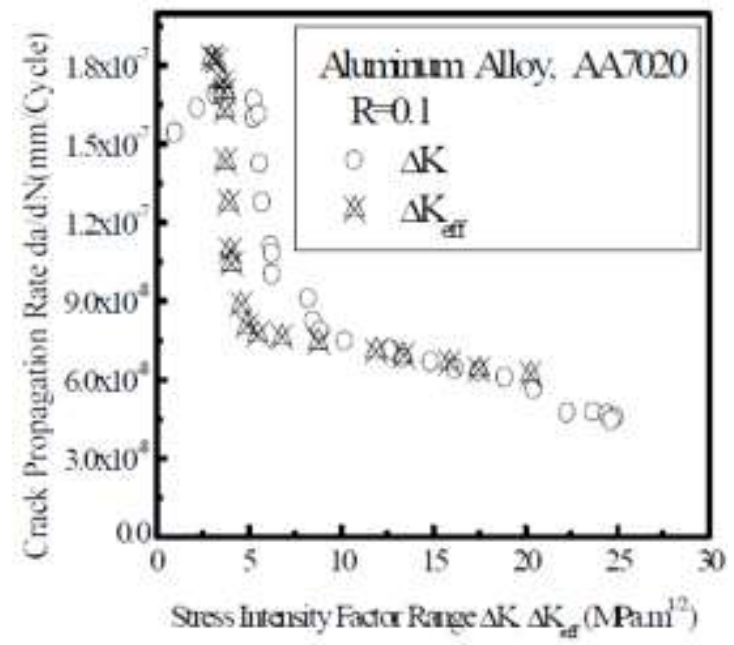

Fig. 2.Relationship between FCP rate and stress intensity factor range for large cracks

Based on fracture surface analysis, it was confirmed that the transition of the operative micromechanisms of fracture has occurred. The transition of fracture mechanism is believed to occur when the cyclic plastic zone size is equal to the average grain size. The cyclic

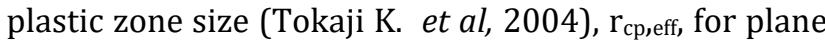
strain state is given by the following equation.

$r_{\mathrm{cp}, \mathrm{eff}}=\frac{1}{2 \sqrt{2 \pi}}\left\{\frac{K_{I C}}{2 \sigma_{y}}\right\}^{2}$

Where, $\sigma_{\mathrm{y}}$ is the yield strength of material.

Substituting $\Delta \mathrm{K}_{\mathrm{eff}}=3: 5 \mathrm{MPa} \sqrt{\mathrm{m}}$ and $\sigma_{\mathrm{y}}=280 \mathrm{MPa}$ into Eq. (1), the $r_{c p \text {,eff }}$ value obtained is approximately $31.17 \mu \mathrm{m}$ which is not in agreement with the average grain size of $50-80 \mu \mathrm{m}$. It is interesting to compare the FCP characteristic of the present Al-Mg-Zn-Zr alloy with that of other light metals, i.e. two types of aluminium alloys, 7075-T6 (Tokaji K, et al, 1990) and 6063- T5(Tokaji K. et al, 2002).

\subsection{Fatigue strength}

The S-N diagram is shown in Figure 3. It is well known that fatigue limit does not exist in non-ferrous alloys, thus fatigue tests were continued until $2.85 \times 10^{4}$ cycles. At $\sigma=110 \mathrm{MPa}$, fatigue failure did not occur, but non-propagating cracks were observed on the specimen surface.

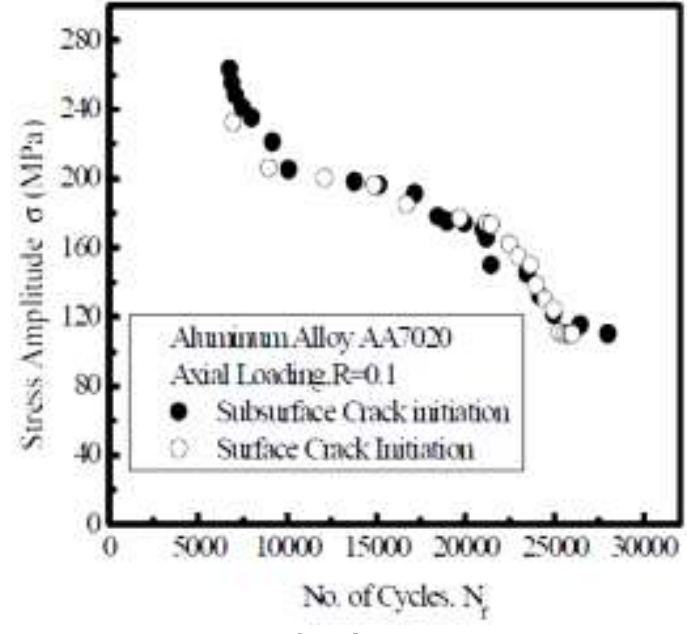

Fig. 3.S-N curves for the 7020-T6 at $\mathrm{R}=0: 1$

\subsection{Surface fracture}

\subsubsection{Crack initiation}

Crack initiation was examined in detail for the main cracks that led to final failure and many other cracks remained on the surface of failed specimens. Consequently, it was found that cracks have initiated within grains (transgranular) or at grain boundaries (intergranular). It can be also seen that initiation in both transgranular and intergranular modes occurred together in nearly $(60: 40)$ not equal amounts. Figure 4 reveals typical examples of SEM micrographs showing crack initiation at two magnifications. Figure $4(a)$ is transgranular mode and intense slip bands can be seen parallel to the severe crack branch, thus the crack generates due to cyclic slip deformation. Figure 4(b) is intergranular mode and intense slip bands are seen on the fracture surface, which have a certain angle against the grain boundary at which the crack initiated. This may indicate that slip bands are major blocked by the grain boundary and thus a stress concentration occurs reasonably, then leading to intergranular crack initiation. The fracture surface exhibits small flat cleaved areas containing small no. of micro-voids. The voids were seen to coalesce to form void lines that are somehow randomly distributed, leading to the development of microscopic and macroscopic cracks both.

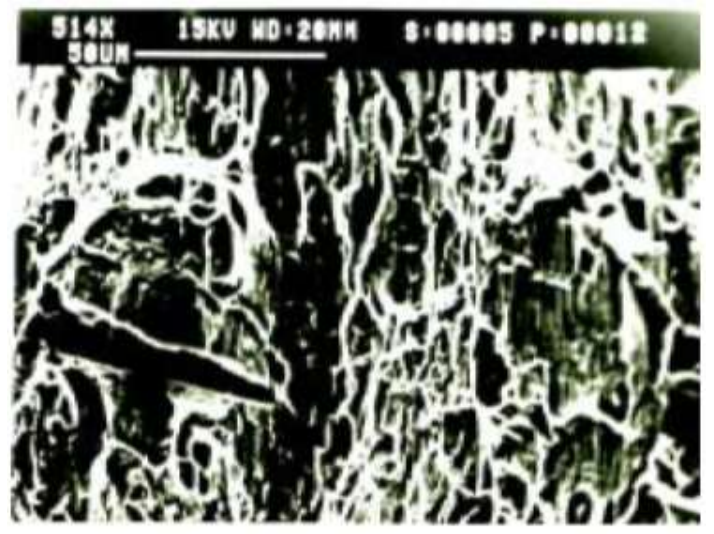

(a) 


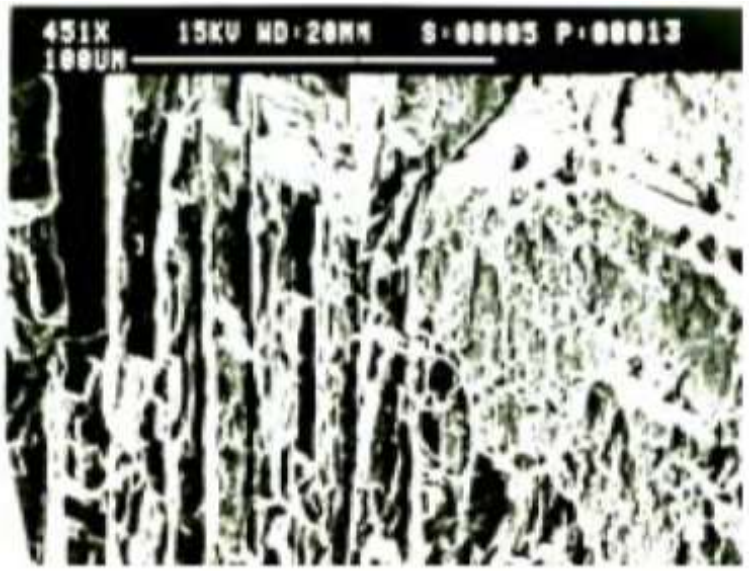

(b)

Fig. 4.SEM micrographexamples of crack initiation at the specimen surface: (a) transgranular $(\sigma=200 \mathrm{MPa})$; (b) intergranular $(\sigma=110 \mathrm{MPa})$.

\subsubsection{Small crack growth}

It should be noted that at $\sigma=110 \mathrm{MPa}$, the crack was no initiated at the interior of the specimen, but it appeared on the surface immediately, indicating that subsurface crack initiation also occurred at very early stage of fatigue life. In addition, at $\sigma=280 \mathrm{MPa}$, multiple cracks initiated, grew and then often coalesced each other. The authors have also indicated that FCP rates for small cracks were often decreased by microstructural barriers such as grain boundary in a wide variety of metals (Tokaji K. et al, 1992). These findings imply that the crack initiation resistance of the present alloy would be significantly low, which is believed to be a cause for the low relative fatigue strength observed. Also suggested from the Figure 2 is the importance of the evaluation on small crack growth behaviour, because fatigue life is mostly dominated by small crack growth. However, some large cracks were observed after $200 \mathrm{MPa}$. Small cracks exhibit the wellknown behaviour in the present alloy, i.e. they can grow below the threshold effective stress intensity factor range, $\Delta \mathrm{K}_{\text {eff,th }}$, for large cracks and show frequent fluctuations in FCP rate. The present Al-Mg-Zn-Zr alloy seems to show more pronounced fluctuations compared with literature of other alloys.

\section{Conclusions}

Axial fatigue tests have been performed using smooth specimens and CT specimens of a hot rolled Al- Mg-Zn$\mathrm{Zr}$ alloy in laboratory at ambient temperature. Fatigue strength and fatigue crack propagation (FCP) characteristic were evaluated and fracture mechanism was discussed on the basis of crack initiation, small crack growth and fracture surface analysis. The conclusions can be made as follows:
1) The relationship between FCP rate and stress intensity factor range, $\Delta \mathrm{K}$, for large cracks consisted of two sections characterized in terms of the effective stress intensity factor range, $\Delta \mathrm{K}_{\text {eff. }}$ This was due to the transition of the operative micro-mechanisms of fracture.

2) The present Al-Mg-Zn-Zr alloy had the medium FCP resistance for large cracks compared to the literature of other two aluminum alloys.

3) Fatigue strength at $10^{4}$ cycles was $110 \mathrm{MPa}$ that led to a considerably low fatigue ratioof 0.1 .Fatigue failure did not occur.

4) Fracture mode changed between 110-200 MPa, above which surface fracture occurred, while below that stress subsurface fracture took place.

\section{Acknowledgements}

The authors are grateful to the IIT Bombay for allowing us to use their laboratory and Hindustan Aeronautics Limited, Bangalore for their support of their research material.

\section{References}

Wang QY, Kawagoishi N, and Chen Q. (2003), Effect of pitting corrosion on the very high cyclelife fatigue behaviour. Scripta Mater, 49,711-16.

Heuler P. andBirk O. (2002), Durability assessment of automotive aluminium parts,FatigueFractEng Mater Struct,25,1135-48.

Mayer H, Papakyriacou M, Zettl B, and Stanzl-Tschegg SE. (2003), Influence of porosity on thefatigue limit of die cast magnesium and aluminium alloys,Int J Fatigue, 25,245-56.

Fatigue crack propagation ASTMSpec. Tech Publ. NO. 415, June (1967).

Proc. Crack Propagation Symp.,CranfieldEngland, October (1961).

Jono M, Song J, Mikami S, and Ohgaki M.(1984), Fatigue crack growth and crack closure behavior of structural materials,JSoc Mater SciJpn, 33,468-74.

Tokaji K, Ogawa T, and Kameyama Y.(1990), The effects of stress ratio on the growth behavior of small fatigue cracks in an aluminum alloy 7075-T6 (with special interest in stage I crack growth),Fatigue FractEng Mater Struct, 13, 411-21.

Tokaji K, and Goshima Y. (2002), Fatigue behaviour of 6063 aluminiumalloy in corrosive environments,JSoc Mater SciJpn, 51,1411-6.

Tokaji K, and Ogawa T. (1992), The growth behaviour of microstructurally small cracks in metals. In: Miller KJ, de los Rios ER, editors. Short fatigue cracks. London: MEP; 85-99.

Thakur A. et al (2007), Stress ratio and fatigue damage map study of hot rolled 7020-T6 aluminum alloy, Materials Science and Engineering A, 454-455, 552-557.

Tokaji K. et al. (2004), International Journal of Fatigue, 26, 1217-1224. 